\title{
CLOZE TESTS AND WORD READING TESTS: ENABLING TEACHERS TO MEASURE LEARNERS' READING-RELATED ABILITIES
}

\author{
Nanda M Klapwijk \\ University of South Africa
}

\begin{abstract}
'How can I measure my learners' reading ability in order to manage my instruction more effectively?' This seems to be the refrain of many teachers these days. However, while teachers are taught new methods of instruction and new reading methods, they do not seem to be taught about reliable ways to measure their learners' reading-related ability independently. In this article, a recommendation is made for the use of two measurements by teachers: a word reading test (which measures word recognition) and Cloze tests (which measure a reader's ability to comprehend at more than word level). While acknowledging the difficulties related to measuring reading ability, in particular comprehension, the author of this article provides evidence that, when combined, a word reading test and a Cloze test can provide teachers with a reliable indicator of their learners' reading-related abilities. The article concludes with a list of benefits that can be gained from obtaining such measurements.
\end{abstract}

\section{INTRODUCTION}

The importance of learners comprehending what they read is undisputed. In fact, Goodman and Goodman (2009:92) go as far as stating that 'there is no reading without reading comprehension'. Research shows that comprehension instruction is important (Durkin, 19781979; Palincsar \& Brown, 1984; Paris \& Hamilton, 2009; Pressley, 2001) and that explicit instruction of reading comprehension strategies is not only effective in increasing learners' comprehension (Block \& Duffy, 2008; Pressley, 2001, 2005; Pressley \& Harris, 1990; Williams, 2008) but also improves self-control and regulating while reading (Haller, Child \& Walberg, 1988; Paris, Wixson \& Palincsar, 1986), affects the use of metacognitive strategies in second-language test performance of low-ability groups (Purpura, 1998), and improves decoding abilities (Van den Bos, Brand-Gruwel \& Aarnoutse, 1998). Vast amounts of literature and research exist about the fact that although reading interventions in schools abound, reading comprehension continues to be a problem for learners worldwide and teachers still do not seem to teach comprehension actively, despite overwhelming evidence in support of comprehension instruction (Pressley \& Harris, 1990; Sailors, 2008; Van Keer, 2004).

\section{THE EFFECT OF COMPREHENSION INSTRUCTION ON LEARNERS}

A variety of reasons exist for the continued lack of comprehension instruction in schools. Sailors (2008) blames a lack of proper teacher education - which effectively means teachers generally remain under-informed about effective comprehension instruction methods (such as 
the use of reading strategies). Preparing teaching material for comprehension instruction (in particular reading strategy instruction) is also perceived to be time consuming (Block \& Duffy, 2008; Pressley \& Beard El-Dinary, 1997). A further reason is that teachers seem to remain unconvinced about the effect of strategy instruction on their learners' progress, that is, they want evidence that it works. Klapwijk and Van der Walt (2011) address this last issue by describing the motivational value for teachers of being able to measure the effect of their comprehension instruction on their learners. They argue that hard evidence of learners' growth in what is effectively an invisible construct (comprehension) can act as motivation for implementation of comprehension instruction. This article adds a further dimension in motivating teachers to take on and improve comprehension instruction: In it, I suggest a way for teachers to obtain a measure of their learners' reading ability for (1) knowledge of where their learners are before instruction ('At what level are my learners now?'), and (2) for repeated, comparative measures once instruction has started taking place ('How has my instruction affected my learners?'). Rather than focusing on why comprehension instruction remains problematic for learners and teachers or on what is not being done at schools in terms of comprehension instruction, I instead argue that if teachers are given the right tools to obtain their own first-hand, reliable knowledge of their learners' reading-related abilities, such knowledge might act as motivation for implementing more effective comprehension instruction.

Williams, Ari and Santamaria (2011: 216) stress the "urgent need to improve the ability to measure reading comprehension ability" to ensure efficient student placement. However, measuring reading comprehension ability is easier said than done. Reading, in particular reading comprehension, is a complicated and multifaceted process affected by multiple factors, such as decoding, vocabulary, fluency, prior knowledge of the topic, and working memory. Each of these aspects has been and continues to be researched in depth by scholars. In the context of this article, the question, therefore, arises: how can teachers, who are generally not qualified researchers, obtain a reliable measure of their learners' reading-related ability? Which aspect(s) of reading should be included in such measurement(s)? Is more than one measure necessary to obtain a fair and valid indication of reading ability? Are easilyobtained and easy-to-use measurements available?

Research seems to support the use of multiple measures for comprehension. Alderson and Banerjee (2002) claim that the use of more than one method of testing is "preferable" when attempting to measure a construct like reading comprehension, while Andreassen and Bråten (2010:263) are of the opinion that more than one measure provides a better view of the contribution of the different skills and processes associated with comprehension. In general, what can be gained from existing research into children's reading comprehension is that word recognition, prior exposure to print, language skills and the role of memory all seem to contribute to comprehension (Goff, Pratt \& Ong, 2005:583). Word recognition in particular is frequently mentioned in research about reading comprehension. Andreassen and Bråten (2010:264-265) describe word recognition skills as a 'very important source of variation' as well as "an important independent predictor" of comprehension in primary school children. However, they also add that the relationship between word recognition and comprehension decreases as the child's age increases. Pretorius and Ribbens (2005:139) describe decoding and word recognition as 'prerequisite skills for successful comprehension', while Rydland, Aukrust and Fulland (2012:478), who studied the contribution of decoding, vocabulary and prior knowledge in predicting comprehension ability, found decoding 'to make a strong contribution to success' in the comprehension measurements they used. Generally, the researchers seem to agree about two things: (1) the more automatic word recognition is present, the more cognitive resources can be allocated to comprehension, and (2) that a 
reader's ability to recognise words does not necessarily lead to the construction of meaning. As Stanovich (2000) maintains, word recognition is a 'necessary but not sufficient condition' for reading comprehension.

Used in conjunction with other information (such as information gained from a Cloze test), word reading tests enable researchers and teachers to form a broad estimate of a learner's reading achievement to aid decisions about appropriate teaching and reading materials, instructional groupings, and so on. In addition, word reading tests can prove useful as an indicator of possible wider reading problems. A wide variety of word reading tests are available. Apart from the Burt Word Reading Test (BWRT), which was used in this study (and is described in more detail in the INSTRUMENTS section), the following word reading tests also exist: the Graded Word Reading Test (developed by Schonell in 1966), the San Diego Quick Assessment (LaPray \& Ross, 1969), the Wide Range Achievement Test (developed by Jastak \& Jastak, 1978) and the St Lucia Graded Word Reading test (Andrews, 1973). The tests, specifically used to measure word recognition, are usually administered individually to readers between 6 and 13 years of age and generally end after a specific number of consecutive words have been misread. A study by Smith and Harrison (1983), which compared the Schonell, the San Diego Quick Assessment, and the Wide Range Achievement tests, showed that 'mean scores were consistent' on two of the tests and 'all correlation coefficients were significant at the .01 level' and indicated that the tests can be used alternatively 'as informal measures for determining reading level estimates'.

However, as was emphasised earlier, reading comprises a complex set of skills - word reading tests provide a measure of only one aspect of reading, namely word recognition. As Clay (1993) states, word reading caters for word-level cues only (word-specific information and sound-symbol correspondences), while reading should ideally use word-level cues in conjunction with sentence-level cues to develop readers' use of multiple cues for solving problems while reading. Cloze tests, which consist of a short piece of text containing full sentences and paragraphs, provide the opportunity to judge learners' higher-level processing skills. Cloze tests have been proven to be highly correlated with virtually any other type of language test, as well as with tests of virtually any language skill and component (Bachman, 1994:177). Cloze tests have been used to 'assess, predict and diagnose reading instructional levels' (Evans \& Balance, 1977:110). Francis (1999:27) states that because Cloze tests constitute 'self-contained, connected and complete segments of discourse' they 'could be considered an integrative measure of reading'. Cloze tests have also, to some extent, been shown to measure readers' use of reading strategies (Ashby-Davis, 1985:587). Cloze tests require a 'constructed response' (Wolf, 1993:474) rather than a 'selected response', as in multiple choice tests. A constructed response could be said to provide a fair indication of a reader's comprehension, since the missing word must be inferred from the text, rather than from eliminating other possible answers or guessing (as in multiple response tests). In other words, as stated by Francis (1999:27), Cloze tests include the 'simultaneous application of vocabulary knowledge, grammatical competence, sentence-level decoding and passage-level comprehension'.

In answer to the questions posed earlier in this section, it would seem that more than one instrument is necessary to measure reading-related abilities, particularly if a measure of overall comprehension ability is to be obtained. In this article, I propose the use of a word reading test, which measures word recognition, combined with a Cloze test, which measures sentence-level cues. I will argue that for teachers' classroom management and instruction purposes, the combined use of these two measures could provide a fair indication of individual reading-related ability. In the sections that follow, I will describe a study in which 
the combination of a word reading test and a Cloze test was used to obtain baseline data about readers' individual reading-related abilities.

\section{METHOD}

The study on which this article is based utilised a mixed-method methodology design. Quantitative as well as qualitative data were gathered, separated by an intervention related to reading comprehension instruction. Quantitative data served to provide a baseline profile of learners' reading-related abilities before the start of the intervention. The results of the baseline data were then compared with measurements taken after the intervention to provide evidence of whether teachers' 'change efforts' had produced results in their learners. This article, however, is focused only on the first quantitative phase of the research, which was aimed at obtaining a view of learners' reading-related ability before the start of the intervention.

\section{Participants}

A sample of convenience (Creswell, 2003:164) was used, whereby teachers and learners were left in their naturally-occurring grade classes. This was done after discussion with the school principal so as not to upset school routines, teachers' schedules and teachers' and learners' comfort zones and to ensure that measurements and research observations were done in environments familiar to learners.

The BWRT and Cloze tests (see INSTRUMENTS section) were administered to 163 learners in Grades 4, 5 and 6. The teachers described the learners' reading ability as 'very poor'. Their opinion is supported by the Annual National Assessment results for the school, in which the school's score for literacy is categorised as 'low'. All the learners who participated in the study were taught in English Home Language classes. The majority of learners were at the correct age expected from the grade levels, with one or two exceptions where leaners were repeating their specific grade.

Table 1: Breakdown of learners by grade and gender

\begin{tabular}{|c|c|c|c|}
\hline Grade & Boys & Girls & Total \\
\hline $\mathbf{4}$ & 25 & 24 & 49 \\
\hline $\mathbf{5 E}$ & 18 & 15 & 33 \\
\hline $\mathbf{5 C}$ & 22 & 13 & 35 \\
\hline $\mathbf{6}$ & 20 & 26 & 46 \\
\hline & $\mathbf{8 5}$ & $\mathbf{7 8}$ & $\mathbf{1 6 3}$ \\
\hline
\end{tabular}

The Burt Word Reading Test (BWRT) was administered individually by the researcher to all participating learners. Once this had been done, the Cloze tests were administered separately to each grade group in their own classrooms. These tests consisted of age-appropriate passages for each grade group and were scored according to the acceptable-answer method (Brown, 1980:311). 


\section{INSTRUMENTS}

The Burt Word Reading Test and Cloze tests were used to gather baseline data about learners' reading-related ability before the start of the intervention.

\section{Burt Word Reading Test}

This test was used to determine learners' reading age at the start of the intervention, and for comparing their measured reading age (Burt age) with their real age. The BWRT is an individually administered test which provides a measure of a reader's word recognition skills. The test is appropriate for use on learners between the ages of 6 to 13 years. The Test Card consists of 110 words printed in decreasing font size and graded in approximate order of difficulty. The test is administered to one learner at a time; the learner is required to read the words on the Test Card aloud without any help from the test administrator. Once the learner has misread or failed to read 10 consecutive words, the test administrator stops the test and adds the number of words read correctly to obtain a total out of 110. The learner's Burt Age is then determined by using the BWRT rubric. The BWRT was performed on 139 learners in the four grade classes, as described in the Participants section. Final scores (counting the number of correct words to obtain a total) were double checked by a separate person.

In the context of this study, the BWRT was administered to obtain reliable baseline data about the research participants' word reading ability. By using this test, it was possible to ensure that data about learners' word reading ability were as recent as possible and based on a recognised, independent measurement. In addition, it was possible to determine the gap (if any) between the measured reading age (Burt age) and learners' real age, and to determine whether the gap between the two ages (where a gap existed) had any correlation with their existing comprehension abilities as measured by the Cloze test.

\section{Cloze test}

A typical Cloze test consists of a short piece of text where the first two sentences have been left intact, and thereafter, a word removed at a set interval (e.g. every $6^{\text {th }}$ or $10^{\text {th }}$ word is removed). Learners are required to provide the missing/removed words. Different versions of the Cloze test exist, such as the maze test where a selection of answers for the missing word is provided and leaners must select the appropriate one, or the standard Cloze test, where no options are provided and learners must decide, on their own, which word best suits the empty space. The standard Cloze test can be marked in two ways, namely, by accepting only the exact answer or by accepting any suitable alternative, whereas the maze Cloze test accepts only the correct option.

In this study, since the BWRT only measures learners' ability to decode (recognise) words, it was deemed necessary to combine the BWRT with a test that provided some measure of learners' ability to comprehend at more than word level. To this end, an age-appropriate Cloze test (see example in Addendum A) was used for each grade group to gain a view of learners' comprehension levels before the research intervention and to determine if there was any correlation between the BWRT results and the Cloze results. To ensure that the Cloze texts' readability levels were measured according to similar standards, existing Cloze tests were taken from an assessment and evaluation handbook used in teacher-training classes at the university to which the researcher was affiliated. The handbook contains age-related Cloze tests based on readability and interest ages. The answers were scored according to the 
acceptable-answer method, which counts any contextually acceptable answer as correct (Brown, 1980: 311).

\section{DATA ANALYSIS}

A Mixed Model Repeated Measures ANOVA was used to compare learners' reading age (as measured by the BWRT) with their real age, and to compare their reading age with their comprehension ability, as measured by the Cloze test. The comparison between reading age and comprehension ability was performed within each grade group and between the respective grade groups to establish whether gaps (where they occurred) not only existed between learners but also between grade groups.

In addition to the ANOVAs, a Pearson correlation was used for determining whether a correlation existed between learners' measured reading ages and their comprehension ability.

\section{RESULTS}

\section{Burt Word Reading Test results}

Once captured and calculated, the BWRT ages were deducted from learners' real ages to determine the difference between the two ages. This difference between learners' real age and reading age was named the reading age difference (RAD). An example of the reading age difference calculation is provided in Table 2 below. Learners are identified as ' $L$ ' followed by the unique number allocated to each learner at the start of the research.

Table 2: Examples of reading age differences (RAD)

\begin{tabular}{|l|l|l|l|}
\hline Learner & Real Age & Burt Age & Reading Age Difference \\
\hline L57 & 10.17 & 10.17 & 0.00 (level) \\
\hline L80 & 10.42 & 12.00 & -1.58 (strong) \\
\hline L81 & 12.33 & 6.92 & 5.42 (weak) \\
\hline
\end{tabular}

Table 2 shows that where a learner's real age was the same as his/her measured Burt reading age, the RAD is described as 'level'. Where a learner's Burt reading age was higher than his/her real age, the RAD is described as 'strong', while learners whose Burt reading age is lower than their real age, are described as having a 'weak' RAD. In other words, the stronger the RAD, the better the learner's word reading skill was deemed to be. Conversely, a weak(er) RAD indicated a low(er) level of word reading skill.

Once the RAD had been calculated for all participating learners, a Mixed Model Repeated Measures ANOVA $(n=283, F(3,140)=18.9, p<0.01)$ was used to determine the mean RAD per group. A summary of the results of these calculations is provided in Table 3 below. 
Table 3: Mean Reading Age Difference (RAD) per group

\begin{tabular}{|l|l|c|c|c|c|}
\hline Group & $\begin{array}{l}\text { Age } \\
\text { Type }\end{array}$ & $\mathbf{N}$ & $\begin{array}{c}\text { Mean } \\
\text { age per } \\
\text { age type }\end{array}$ & $\begin{array}{c}\text { Standard } \\
\text { Deviation }\end{array}$ & $\begin{array}{c}\text { Mean } \\
\text { reading age } \\
\text { difference }\end{array}$ \\
\hline 4 & Real & 46 & 10.08 & 0.63 & \multirow{2}{*}{1.7} \\
\cline { 2 - 5 } & Burt & 42 & 8.38 & 2.10 & \\
\hline 5 (control) & Real & 35 & 10.87 & 2.81 & \multirow{2}{*}{1.6} \\
\cline { 2 - 5 } & Burt & 35 & 9.27 & 2.47 & \multirow{2}{*}{2.36} \\
\hline $5 \mathrm{E}$ & Real & 31 & 11.33 & 0.77 & \multirow{2}{*}{1.38} \\
\cline { 2 - 5 } & Burt & 31 & 8.97 & 1.73 & \\
\hline 6 & Real & 32 & 12.30 & 0.61 & \\
\cline { 2 - 5 } & Burt & 31 & 10.92 & 1.87 & \\
\hline
\end{tabular}

Having determined the individual learners' reading age difference as well as the mean reading age difference between the participating grade groups, and the mean reading age per group, a comparison was done with the results of the Cloze test to determine whether a correlation existed between reading and comprehension skills.

\section{Cloze test results}

Separate age-appropriate Cloze tests were administered to each grade group to obtain some indication of their comprehension ability (higher-level processing ability) before the start of the research intervention, and to determine whether there was any correlation between learners' comprehension ability (as measured by the Cloze test) and their word reading skills (as measured by the Burt Word Reading Test). Once the tests had been scored, the average score per grade was calculated (in Excel). The average score per grade, displayed as a percentage, is provided in Table 4, along with the mean RAD per group.

Table 4: Average Cloze Test score

\begin{tabular}{|l|l|c|c|}
\hline Group & $\mathbf{N}$ & $\begin{array}{c}\text { Average Cloze } \\
\text { Score as a \% }\end{array}$ & $\begin{array}{c}\text { Mean reading age } \\
\text { difference in years }\end{array}$ \\
\hline 4 & 46 & 40.4 & 1.7 \\
\hline $5 \mathrm{C}$ & 35 & 47.9 & 1.6 \\
\hline $5 \mathrm{E}$ & 30 & 44.8 & 2.36 \\
\hline 6 & 44 & 46.9 & 1.38 \\
\hline
\end{tabular}


As is evident from Table 4, there is no significant difference in the average Cloze score of the respective groups. Based on these results, no correlation between learners' comprehension ability (as measured by the Cloze test) and their word reading skills (as measured by the Burt Word Reading Test) seemed possible. However, at an individual score level, that is, when comparing individual RAD values with Cloze test scores, there did seem to be a relationship.

\section{Relationship between reading age difference and comprehension}

Overall, the comparison of RAD and Cloze test scores showed a relationship between a weak RAD (weak/er word reading skills) and low Cloze test scores (low/er levels of comprehension). The low Cloze score $=$ weak $R A D$ trend was evident throughout in comparisons between individual learners' scores. The opposite also generally seemed to hold true: the strong(er) the word reading skill (i.e. the stronger the RAD), the higher the comprehension test score.

Table 5 lists examples from each relationship per group to illustrate the strong $R A D=h i g h$ Cloze score point. The top four examples in the table represent learners with a weak RAD, while the bottom four examples represent learners with a strong RAD

Table 5: Cloze test score vs. reading age difference

\begin{tabular}{|l|l|c|c|}
\hline Group & Learner & $\begin{array}{c}\text { Cloze score } \\
\mathbf{\%}\end{array}$ & $\begin{array}{c}\text { Reading age } \\
\text { difference }\end{array}$ \\
\hline 4 & L9 & 0 & 6.17 \\
\hline $5 \mathrm{C}$ & L90 & 40 & 4.75 \\
\hline $5 \mathrm{E}$ & L50 & 20 & 4.33 \\
\hline 6 & L121 & 45 & 3.08 \\
\hline \multicolumn{4}{|l}{} \\
\hline 4 & L26 & 72 & -1.67 \\
\hline $5 \mathrm{C}$ & L104 & 80 & -2.33 \\
\hline $5 \mathrm{E}$ & L51 & 80 & -0.58 \\
\hline 6 & L139 & 90 & -1.00 \\
\hline
\end{tabular}

However, despite the fact that the trend of a strong $R A D=$ high Cloze score and vice versa held true for the majority of learners, there were some exceptions to both the aforementioned trends. For example, L17 (Grade 4), with a weak RAD (5.17), scored 78\% in the Cloze test and L21 (Grade 4), with a strong RAD (-1.42), scored only 34\% in the Cloze test. Furthermore, there were examples of learners with similar RAD values who showed vast differences in their Cloze results. For example, L58 and L60 (both from Grade 5E) both measured a strong RAD (-0.17) but scored $90 \%$ and $45 \%$ respectively in the Cloze test.

In order to obtain a better view of individual Cloze scores in comparison to their RAD values, a Pearson correlation was performed on the data and presented in a scatter plot, as illustrated in Figure 1. 


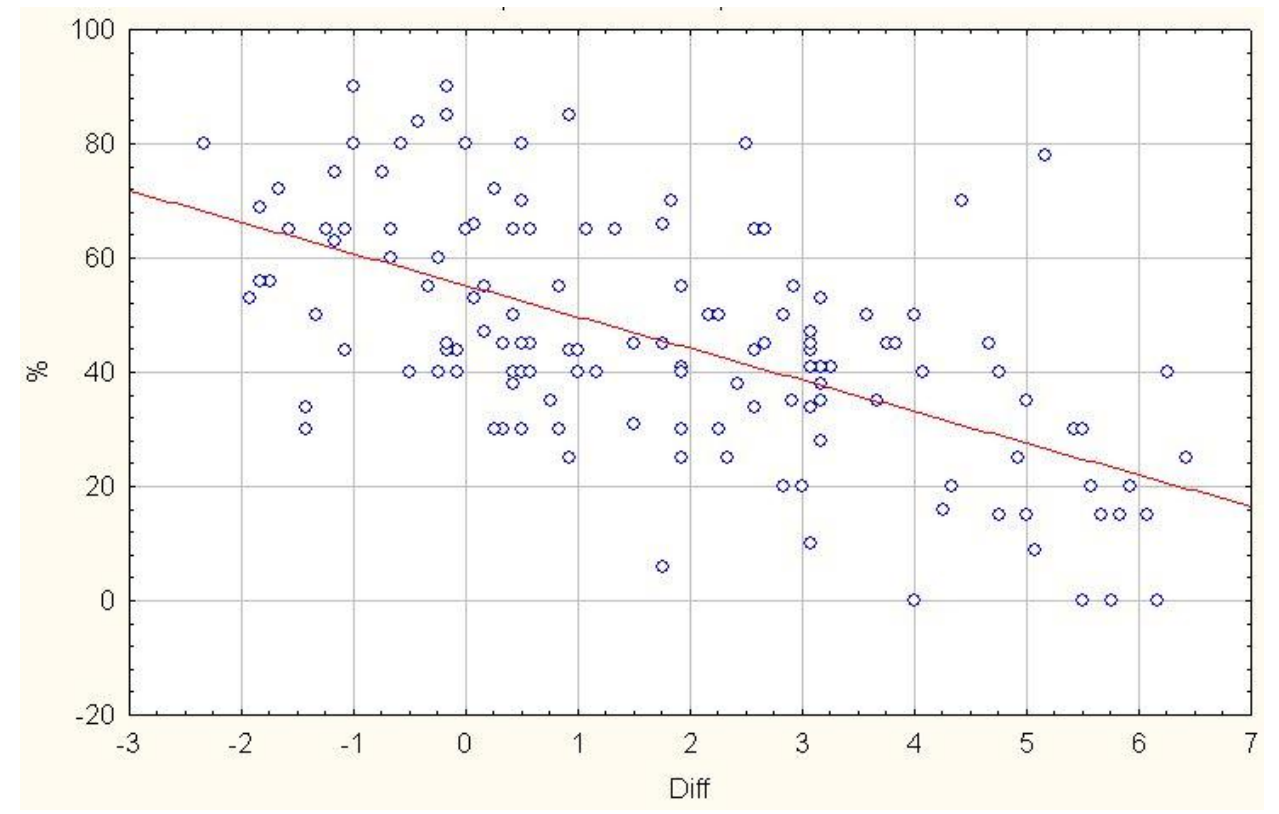

Figure 1: Scatter plot of mean reading age difference vs. Cloze scores

In Figure $1(\mathrm{r}=-0.58, \mathrm{p}<0.01)$, each of the circles represents an individual learner in the four groups $(4,5 \mathrm{C}, 5 \mathrm{E}$ and 6$)$ for whom both a real age and Burt age were measured. The $\mathrm{Y}$ axis represents the score (as a percentage) obtained in the Cloze test, whereas the $\mathrm{X}$ axis represents the reading age difference (RAD). On the $X$ axis ' 0 ' (zero) represents learners whose real age and Burt age are the same (there were only two). The positive and negative numbers on either side of zero on the $\mathrm{X}$ axis represent the range of reading age differences measured in the data, namely from as high as a strong RAD of three years (i.e. learners whose Burt reading age is three years higher than their real age), to a weak RAD of nearly seven years (where learners' Burt reading age is up to seven years lower than their real age). The diagonal red line represents the simple regression line of RAD on the Cloze score; the negative slope of the line indicates the negative relationship between RAD and Cloze scores which - as discussed earlier - shows that the weaker the RAD, the lower the Cloze score.

Although the majority of learners with a weak RAD generally obtained a low Cloze score, there were a number of exceptions which, at least as far as the data for this research are concerned, seems to indicate that reading comprehension is determined by more than word reading skill, and conversely, that strong word reading skills do not necessarily ensure good comprehension.

In summary, the data show the following:

- The majority $(76 \%)$ of learners who participated in the intervention showed a weak reading age difference (i.e. their reading age was lower than their real age), which means that the majority of learners read at a level that was generally lower than what it should have been in their respective grades and for their respective ages.

- Weak reading age differences were associated with lower comprehension ability and vice versa. Furthermore, as indicated by the significant correlation of $r=-0.58, p<0.01$ (see Figure 1) there seems to be a fairly conclusive link between poor word reading skills (as measured by the Burt Word Reading Test) and poor reading comprehension (as measured by the Cloze test). 
However, despite the correlation between poor reading skills and poor comprehension, as found in this study, it is important to reiterate that comprehension is a complicated construct affected by multiple factors, of which word reading ability is merely one. In this article, I recognise the complexity inherent in comprehension and do not attempt to claim a conclusive link between word reading and comprehension ability. Instead, I suggest that the combined application of a word reading test and Cloze tests is a useful, if not indispensable, way to provide teachers with a fair measure of their learners' reading ability, and that being able to obtain some measure of reading ability is crucial to effective instruction, classroom management and assessment.

\section{CONCLUSION}

Earlier in the article, Williams et al. (2011) are quoted as describing the urgent need to measure reading comprehension ability for efficient student placement. As a result of my study for this article, I reason that measuring learners' reading-related ability can do much more than assist with efficient placement. If performed in a sustainable manner and as an integral part of overall language teaching, such measurements may also, over time,

1. provide tangible evidence (quantitative data) of learners' development and growth in reading comprehension,

2. give teachers an indication of the effectiveness of their comprehension instruction,

3. assist teachers in formulating more accurate and realistic teaching objectives,

4. enable teachers to manage their learners according to their individual abilities,

5. assist teachers in selecting ability-appropriate reading material (as opposed to ageappropriate reading material),

6. set sustainable development objectives at class and at school level,

7. encourage increased interest in improving comprehension instruction methods, both at classroom and school level, and

8. act as an indicator of possible wider reading problems in individual learners.

Both the Burt Word Reading Test and the Cloze test are easy to implement; no specialist knowledge is required and both measures can be applied as often as deemed necessary. The Burt word test is free and freely available. Compiling a Cloze test from an age-appropriate text is not difficult. This article provides evidence that their combined use provides a fair indication of learners' individual reading-related ability. Above all, the measurements from these two tests provide teachers with ongoing, independent measurements at school and classroom level rather than simply depending on - and waiting for - annual national literacy assessments. Simply put, it puts control of learners' development where it belongs: in teachers' hands.

\section{REFERENCES}

ALDERSON, JC \& J BANERJEE. 2002. Language testing and assessment (Part 2). Language Teaching 35(2):79-113. 
ANDREASSEN AND BRÅTEN, 2010. Examining the prediction of reading comprehension on different multiple-choice tests. Journal of research in reading, 33(3):263-283

ASHBY-DAVIS, C. 1985. Cloze and comprehension: A qualitative analysis. Journal of Reading, 28(7):585-589.

BACHMAN, LF. 1994. The trait structure of Cloze test scores. In Oller, JW \& J Jonz (Eds.). Cloze and coherence. Cranbury, NJ: Associated University Press.

BLOCK, CC \& GG DUFFY. 2008. Research on teaching comprehension: Where we've been and where we're going. In Block, CC \& S.R Parris,. (Eds.) Comprehension instruction: Research-based best practices. New York, NY: The Guilford Press.

BROWN, JD. 1980. Relative merits of four methods for scoring Cloze tests. Modern Language Journal, 64(3):311-317.

CLAY, MM. 1993. Reading recovery: A guidebook for teachers in training. Auckland, NZ: Heinemann Education (NZ).

CRESWELL, JW. 2003. Research design: Qualitative, quantitative and mixed method approaches. Thousand Oaks, CA: Sage.

DURKIN, K. 1978. What classroom observations reveal about reading comprehension instruction. Reading Research Quarterly, 14(4):481-533.

EVANS, RV \& CT Balance,. 1977. Cloze scores and writing criteria as predictors of instructional level. Journal of Educational Research, 71(2):110-113.

FRANCIS, N. 1999. Applications of Cloze procedure to reading assessment in special circumstances of literacy development. Reading Horizons, 40(1):23-46.

GOFF, DA, C PRATT \& B ONG. 2005. The relations between children's reading comprehension, working memory, language skills and components of reading decoding in a normal sample. Reading and Writing, 18(7-9):583-616.

GOODMAN, KS \& YM GOODMAN. 2009. Helping readers make sense of print: research that supports a whole language pedagogy. In Israel, S.E. \& GG Duffy (Eds.). Handbook of research on reading comprehension. New York, NY: Routledge.

HALLER, EP, DA CHILD. \& HJ WALBERG. 1988. Can comprehension be taught? A quantitative synthesis of 'metacognitive' studies. Educational Researcher, 17(9):5-8.

JASTAK, JF \& SR JASTAK. 1978. Wide range achievement test: Manual. Wilmington, DE: Jastak.

KLAPWIJK, NM \& C VAN DER WALT. 2011. Measuring reading strategy knowledge transfer: Motivation for teachers to implement reading strategy instruction. Per Linguam, 27(1):25-40.

LAPRAY, M \& R ROSS.1969. The Graded Word List: Quick gauge of reading ability. Journal of Reading, 12:305-307 
PALINCSAR, AS \& AL BROWN. 1984. Reciprocal teaching of comprehension-fostering and comprehension-monitoring activities. Cognition and Instruction, 1(2):117-175.

PARIS, SG, KK WIXSON \& AS PALINCSAR. 1986. Instructional approaches to reading comprehension. Review of Research in Education, 13:91-128.

PARIS, SG \& EE HAMILTON. 2009. The development of children's reading comprehension. In Israel, S.E. \& GG Duffy. (Eds.). Handbook of research on reading comprehension. New York, NY: Routledge.

PRESSLEY, M. 2001. Comprehension instruction: What makes sense now, what might make sense soon. Reading Online, 5(2) [Online]. Available: http://www.readingonline.org/articles/art_index.asp?HREF=/articles/handbook/pressley /index.html

PRESSLEY, M. 2005. Reading instruction that works: A case for balanced teaching. New York, NY: The Guilford Press.

PRESSLEY, M \& P El-Dinary. 1997. What we know about translating comprehension strategies instruction research practice. Journal of Learning Disabilities, 30:486-488.

PRESSLEY, M \& KR HARRIS. 1990. What we really know about strategy instruction. Educational Leadership, 48(1):31-34.

PRETORIUS, EJ \& R RIBBENS. 2005. Reading in a disadvantaged high school: Issues of accomplishment, assessment and accountability. South African Journal of Education, 25(3): 139-147.

PURPURA, JE. 1998. Investigating the effects of strategy use and second language test performance with high- and low-ability test takers: A structural equation modeling approach. Language Testing, 15(3):333-379.

RYDLAND, V, VG AUKRUST \& H FULLARD. 2012. How word decoding, vocabulary and prior topic knowledge predict reading comprehension. A study of language-minority students in Norwegian fifth grade classrooms, Reading and Writing, 25:465-482.

SAILORS, M. 2008. Improving comprehension instruction through quality professional development. In Israel, SE \& GG Duffy, (Eds.) Handbook of Research on Reading Comprehension. New York, NY: Routledge.

SCHONELL, FJ. 1966. The psychology of teaching reading. London, UK: Oliver \& Boyd.

SMITH, CF \& MD HARRISON. 1983. A comparative analysis of three widely used graded word reading tests. Paper presented at the Annual Meeting of the Great Lakes Regional International Reading Association, October 5-8, 1983.

STANOVICH, KE. 2000. Progress in understanding reading: Scientific foundations and new frontiers. New York, NY: Guilford.

VAN DEN BOS, KP, S BRAND-GRUWEL \& CAJ AARNOUTSE. 1998. Text comprehension strategy instruction with poor readers. Reading and Writing: An Interdisciplinary Journal 10(6):471-498. 
VAN KEER, H. 2004. Fostering reading comprehension in fifth grade by explicit instruction in reading strategies and peer tutoring. British Journal of Educational Psychology 74(1):37-70.

WILLIAMS, JP. 2008. Explicit instruction can help primary students learn to comprehend expository text. In Block, CC \& SR Parris (Eds.) Comprehension Instruction: Research-based best practices. New York, NY: The Guilford Press.

WILLIAMS, RS, O ARI \& CN SANTAMARIA. 2011. Measuring college students' reading comprehension ability using Cloze tests. Journal of Research in Reading 34(2):215231.

WOLF, DF. 1993. A comparison of assessment tasks used to measure FL reading comprehension. The Modern Language Journal, 77(4):473-489.

\section{BIOGRAPHICAL NOTE}

Nanda Klapwijk is a Senior Lecturer in Applied Linguistics at the University of South Africa. Her research interests include reading comprehension instruction, multilingual (language) learning and technology-assisted language learning.

Email: klapwn1@unisa.ac.za 


\section{Addendum A - Cloze Test for Grade 4}

Many different people are car drivers.

Some drivers men, and some drivers women.

Some drivers are , and some drivers are

But all of these people to drive fast around track.

There are lots different racetracks.

Some are tracks, and some are tracks. Some are straight , and some are curved

Some are long tracks, some are short tracks. are different, too. are made for the they will be driven at and the speeds they be driven at.

But all have to be safe.

All race car go to a car school.

They are shown to turn and pass stop.

They are shown to drive safely at speeds.

They are shown to do if they

They have to learn these things because driving race car is risky. race car drivers must a seat belt. 